\title{
Principios para la interpretación de la Constitución en la jurisprudencia de la Corte Constitucional colombiana
}

Juan Carlos Moncada Zapata

Con frecuencia encontramos en la doctrina jurídica una idea según la cual se debe reconocer a priori la existencia de ciertos principios considerados peculiares o exclusivos de la interpretación constitucional. Cuando se trata de enunciar tales principios, generalmente se mencionan los siguientes: de unidad de la constitución, de armonización u optimización, de interpretación conforme a la constitución ${ }^{1}$ de funcionalidad, de eficacia o efectividad; ${ }^{2}$ de favor libertatis, de continuidad de la jurisprudencia, de presunción de legitimidad de las leyes, de prudencia; ${ }^{3}$ fundamentalidad, limitación, responsabilidad, control, razonabilidad, perdurabilidad, ${ }^{4}$ etc.

Sin embargo, la enunciación de los principios es mucho más compleja cuando se trata de estudiarlos con arreglo a un ordenamiento jurídico en particular por la circunstancia de que son tan relativos y variables como las mismas constituciones, sin olvidar que el método de trabajo de los tribunales está necesariamente vinculado a casos concretos de lo cual se derivan infinidad de principios nuevos y modalidades de su aplicación.

1 Klaus Stern. Derecho del Estado de la República Federal Alemana. Centro de Estudios Constitucionales, Madrid, 1987. p. 291 y ss.

2 Antonio E. Pérez Luño. Estado de derecho, derechos humanos y Constitución. Editorial Tecnos, Madrid, 4a edición, 1991. p. 276 - 278.

3 Arturo Hoyos. La interpretación Constitucional. Editorial Temis, Santafé de Bogotá, 1993. p. 23 y ss.

4 Germán Bidart Campos. El derecho de la Constitución y su fuerza normativa. Ediar, Bs. As., 1995. p. 104 y ss. 
El caso colombiano es bastante elocuente a este respecto. El Título Primero de la Constitución colombiana (en adelante C.c.) se denomina "De los Principios Fundamentales", mientras que al menos veinte normas constitucionales se refieren a principios de toda índole. De otra parte, resulta fácil verificar cómo la Corte Constitucional ha inventado infinidad de principios o ha creído verlos implícitos en ciertas normas constitucionales o legales.

A pesar de lo anterior, no me propongo estudiar los principios constitucionales en general, sino una clase especial de principios. Existe, en efecto, un significado de la palabra principio jurídico que se utiliza para aludir a normas que cumplen estas condiciones: a) presuponen la existencia de otras normas y se refieren a ellas (o reglas de primer grado); b) se dirigen a quienes deciden, es decir, primordialmente a los operadores jurídicos; c) proporcionan una guía acerca de cómo y cuándo han de usarse las normas (reglas de segundo grado) sobre las que versan, qué alcance darles, cómo combinarlas, cuándo otorgar precedencia a alguna de ellas y, finalmente, d) exhiben cierta indiferencia o neutralidad de contenido. ${ }^{5}$

Una norma como la del artículo $4^{\circ}$ de la C. c., v.gr., a cuyo tenor «en todo caso de incompatibilidad entre la Constitución y la ley u otra norma jurídica, se aplicarán las disposiciones constitucionales», parece cumplir con los requisitos antes señalados: presupone la existencia de otras normas, está dirigida a los operadores jurídicos, proporciona una guía acerca de cuáles normas del sistema tiene precedencia en eventos de incompatibilidad $y$, finalmente, resulta indiferente frente al contenido de las normas incompatibles.

Con el modelo descrito me propongo verificar que la C.c. acoge explícitamente otros tantos principios de esta clase; es posible constatar, asimismo, que la jurisprudencia de la Corte Constitucional, en su corto período de existencia de ocho años, ha incorporado a su bagaje

5 Esta caracterización ya clásica de cierto tipo de principios se debe a Genaro Carrió, diseñada con el propósito de refutar una crítica al positivismo jurídico planteada por Dworkin en 1967. Según Dworkin, la obsesión por el llamado «modelo de reglas" no dejaría ver el papel central que en la práctica del derecho desempeñan los principios jurídicos. Carrió se preocupaba por saber si las pautas o criterios llamados principios jurídicos son parte del derecho tal y como éste se entiende desde el punto de vista del positivismo jurídico hartiano. Cfr. Principios jurídicos y positivismo jurídico. Abeledo Perrot, Bs. As., 1970, p. 21 y ss. 
hermenéutico muchos otros que considera implícitos en el sistema constitucional o bien toma prestados de la doctrina, o bien recoge de normas legales para aprovecharlos en la interpretación de normas constitucionales, como los siguientes:

1. Principio de prevalencia de la constitución o principio de constitucionalidad

2. Principio de igualdad en constitucionalidad

3. Principio de eficacia del texto a interpretar

4. Principio de ponderación

5. Principio de armonización concreta

6. Principio de efectividad de los derechos fundamentales

7. Principio de conservación del derecho

8. Principio de interpretación conforme a la Constitución

9. Principio del efecto útil

10. Principio de interpretación razonable

11. Principio de interpretación sistemática

12. Principio de interés superior del menor

13. Principio de la unidad constitucional

14. Principio del menor daño constitucional

15. Principio pro favor libertatis

16. Principio de proporcionalidad

17. Principio de prevalencia de tratados internacionales

18. Principio de la presunción de racionalidad del legislador

19. Principio de decisión normativa de las mayorías políticas

20. Principio de libre iniciativa legislativa

21. Principio de mensurabilidad

22. Principio de participación democrática

23. Principio de universalidad

24. Principio de racionalidad

25. Principio de razón suficiente

26. Principio de prevalencia de la justicia material

27. Principio de prevalencia de la realidad, y

28. Principio de primacía del derecho sustancial

Este es el elenco de principios que aparentan reunir las cualidades anotadas, explícitos e implícitos en la C.c., sin pretender que el elenco esté completo. En adelante trataremos de esclarecer cuál es su función, 
de dónde surgen y cuáles han sido las pautas jurisprudenciales para su utilización y aplicación.

\section{Principio de prevalencia de la Constitución o principio de constitucionalidad.}

Este principio encuentra su fundamento expreso en el artículo $4^{\circ}$ de la C.c., según el cual las incompatibilidades entre normas de toda jerarquía y las normas constitucionales se deben resolver dando prelación a la Constitución. En abstracto, este principio resulta fácil de entender si se reconoce la idea de que la Constitución es una norma rígida. Sin embargo, las dificultades prácticas de su aplicación se reflejan en las numerosas pautas que ha dado la jurisprudencia de la Corte Constitucional. Veamos:

\subsection{Sentencia S. T-556/98:}

La aplicación de la C.c. es preferente aún en presencia de normas inferiores que en apariencia tengan un carácter imperativo.

$\square$ El juicio que está llamado a hacer el juez de tutela no es de naturaleza legal.

$\checkmark$ La tarea del fallador consiste en lograr la plena efectividad de la Constitución frente a la ley.

$\square$ El artículo $4^{\circ}$ de la Carta contempla el principio de constitucionalidad.

La autoridad pública que detecte una contradicción con la C.c. está en la obligación de inaplicar el precepto subalterno o de menor jerarquía.

La inaplicación tiene lugar sólo para casos concretos y con efectos particulares.

$\square$ Existe un principio que establece una presunción de constitucionalidad de las normas; pero tal principio es desvirtuable por vía general en la Corte Constitucional o por vía concreta en el caso de las autoridades públicas.

Resulta esencial que en realidad exista incompatibilidad de dos normas.

- Son incompatibles dos normas que, dada su mutua contradicción, no pueden imperar ni aplicarse al mismo tiempo. 
$\square$ La incompatibilidad debe implicar una oposición flagrante o grave u antagonismo ostensible o saltar a la vista del intérprete, haciendo superflua cualquier elaboración jurídica.

$\square$ El principio de constitucionalidad pretende garantizar la coherencia del sistema jurídico e irradiar la creación, interpretación, aplicación y ejecución de las normas de rango inferior.

- Una cosa es la norma y otra bien distinta su aplicación a un caso concreto (Cfr. Corte Constitucional. Sentencia T-614 de 1992).

\subsection{Sentencia SU-640/98:}

$\square$ Los principios de supremacía e integridad de la Constitución se traducen en la destacada ubicación de la Corte Constitucional en el concierto de los poderes del Estado.

La supremacía garantiza la adecuada defensa y vigor de la Carta.

$\checkmark$ La supremacía se garantiza asegurando la uniformidad de la interpretación constitucional.

$\square \mathrm{La}$ institución de la cosa juzgada constitucional garantiza el carácter general de las sentencias de inexequibilidad proferidas por la Corte Constitucional que, por lo tanto, están dotadas de efectos erga omnes.

$\square$ La revisión eventual de las sentencias de tutela contribuye a homogeneizar la interpretación constitucional de los derechos fundamentales y a garantizar la supremacía.

\section{Principio de igualdad en constitucionalidad.}

La Corte ha derivado este principio del artículo $13^{\circ}$ de la C.c. para afirmar que el juez debe asumir un cierto comportamiento interpretativo en los casos que implican una violación del derecho de igualdad, lo cual se traduce en el deber de hacer un juicio de mayor o menor intensidad en el caso concreto, y según las siguientes pautas:

\subsection{Sentencia C-318/98:}

$\square$ La intensidad del test de igualdad no es siempre la misma o, dicho de otra manera, el juicio en casos de igualdad es más o menos estricto.

$\square$ La intensidad depende del patrón que se utilice para diferenciar a las personas o grupos afectados por la norma y depende también de 
la relevancia constitucional de las cargas o beneficios que se distribuyen diferencialmente.

Si el legislador utiliza una de las pautas o patrones de diferenciación que menciona expresamente el artículo $13^{\circ}$ de la C.c., el test debe ser estricto.

Si los beneficios y las cargas se relacionan con un derecho de origen legal, el juicio debe ser intermedio.

En los casos de marcado predominio del principio democrático, el test debe ser débil.

$\square$ Un juicio de mediana intensidad supone un análisis de la finalidad de la medida en términos de suficiencia o estricta proporcionalidad.

$\checkmark$ Un test fuerte de igualdad exige una demostración del legislador en el sentido de que la medida es indudablemente útil y necesaria para alcanzar una finalidad constitucionalmente imperativa.

\subsection{Sentencia C-360 de 1996:}

La Corte Constitucional precisó que en las asignaciones de gasto público el juicio de igualdad se torna en extremo débil o flexible porque:

En estos eventos debe primar el principio democrático.

Tal principio consiste en la facultad de definir, según criterios de oportunidad y de conveniencia, la destinación de los recursos públicos.

- Sólo procederá un reproche constitucional en los siguientes eventos: cuando el legislador desconoce normas constitucionales que definan claramente los criterios de distribución de los recursos públicos; cuando el canon de diferenciación responde a uno de aquellos claramente proscritos por la C.c., o si resulta flagrante la violación de normas superiores como la que consagra la igualdad de oportunidades sin que exista una justificación compatible con los mandatos contenidos en la Constitución.

\section{Principio de eficacia del texto a interpretar.}

Este principio, de conformidad con el cual la interpretación del derecho debe ofrecer resultados funcionales, no tiene encuadre expreso en la Constitución y se rige por las siguientes pautas: 


\subsection{Sentencia C-112/96:}

$\square$ Se presume la racionalidad del legislador.

$\square$ Se presupone que quien dicta las normas lo hace con un propósito claro.

Todo orden jurídico presupone una lógica interna.

El intérprete debe asumir como pauta o directriz interpretativa que el ordenamiento es sistemático y coherente.

$\square$ El intérprete debe desechar aquellas interpretaciones de un enunciado normativo que den lugar a una proposición absurda.

\section{Principio de ponderación.}

Principio implícito que opera para casos de colisión entre derechos constitucionales, entre principios, entre derechos y principios, entre derechos y garantías institucionales, etc., sin norma expresa en la C.c. y según los siguientes criterios:

\subsection{Sentencia T-575/95:}

$\square$ La exigencia de unidad constitucional exige interpretar la constitución como un todo armónico y coherente.

$\square$ La ponderación está ligada al principio de armonización que impide que se busque la efectividad de un derecho mediante el sacrificio de otro y exige tener en cuenta todos los intereses en juego.

El intérprete debe maximizar la efectividad de cada derecho.

$\square$ Las colisiones de derechos constitucionales se resuelven ponderando.

$\square$ La ponderación no debe ser superficial ni puede basarse en prelaciones abstractas de los bienes en conflicto.

\subsection{Sentencia T-425/95:}

El juez debe ponderar los casos de colisión de derechos constitucionales.

$\square$ Ponderar es buscar un equilibrio de necesidades de las personas enfrentadas.

$\square$ La ponderación se justifica en el deber que tienen las personas de respetar derechos ajenos o deber de autocontención. 
La personas deben ser responsables, reflexivas y consideradas con los demás en ejercicio de sus derechos y medir los efectos de sus acciones hacia terceros.

$\square$ La ponderación se hace necesaria porque así lo exige la finalidad social del Estado de garantizar la efectividad de los principios.

\subsection{Sentencia T-322/96:}

$\square$ Las colisiones se presentan también entre derechos fundamentales y garantías institucionales.

$\square$ Las garantías institucionales no son absolutas.

$\square$ Ponderar es buscar soluciones adecuadas a las colisiones.

$\square$ La ponderación implica que no puede desaparecer una de las normas en conflicto.

$\square$ Sólo ponderando se conoce la prelación que debe regir en el caso concreto.

En esta misma sentencia la Corte aclaró que la garantía institucional es una técnica de protección constitucional a ciertas instituciones típicas y necesarias para la organización política, que funciona como límite para el legislador cuando las regula, y asegura que no se suprima o se desfigure su imagen maestra (V.gr., la inviolabilidad de opinión de congresistas: su imagen maestra se concretaría en la función de control político). Mientras los derechos fundamentales tienen una finalidad inmediata, las garantías tendrían una finalidad mediata.

\section{Principio de armonización.}

Es otro principio implícito que no encuentra raigambre normativa clara en la C.c., si bien la Corte Constitucional se ha basado expresamente en la doctrina de Klaus Stern para quien: “Una norma constitucional no debe ser interpretada de forma aislada; la constitución constituye una unidad [...]. Las normas constitucionales que están en una relación de tensión recíproca, tienen que ser "armonizadas", ser puestas en concordancia la una con la otra [...]. De la unidad de la constitución se deduce la tarea de "optimización" o "armonización" de las normas constitucionales [...] $»^{6}$.

6 Stern. Op cit. pp. 291, 293 y 294. 
Es quizás el principio más recurrido para solucionar casos en la jurisprudencia de la Corte, sin que pueda distinguírselo claramente del principio de ponderación. Cabría decir, quizás, que mientras la ponderación atiende a los intereses en juego, la armonización se refiere a las normas que regulan tales intereses. Las pautas en que se apoya son las siguientes:

\subsection{Sentencia C-255/97:}

La Constitución debe ser abordada como un sistema armónico y coherente.

$\checkmark$ La aplicación de una norma constitucional no debe contradecir o agotar el contenido de otras disposiciones constitucionales.

Deben preferirse las interpretaciones que permitan la máxima efectividad de todas las normas constitucionales.

\subsection{Sentencia C-444/95:}

Una norma no debe ser interpretada en forma aislada porque la Constitución es una unidad.

- Todas las normas están en tensión recíproca, de lo cual se deriva que las normas deben ser puestas en concordancia unas con otras.

De la unidad se deduce la tarea de armonizar y optimizar las normas constitucionales.

Este es un fallo interesante. La Corte Constitucional reconoció que existe una incongruencia constitucional entre la disposición que asigna a la Policía Nacional naturaleza civil y la que ordena que los delitos cometidos por sus miembros en servicio activo y por razón del mismo, sean de conocimiento de las cortes marciales o tribunales militares pues, siendo coherentes, tal juzgamiento debería estar a cargo de autoridades civiles. La Corporación dijo, sin embargo, que la anomalía debía ser corregida mediante una reforma constitucional y que su papel, ante casos como éste debía ser el de dar aplicación al denominado "principio de armonización", para lograr mediante una interpretación sistemática hacer congruentes los distintos preceptos constitucionales que regulan el asunto materia de debate, teniendo en cuenta que, aun ante la incongruencia anotada, la Corporación no puede desconocer el con- 
tenido del artículo $221^{\circ}$ superior, disposición que no resulta irreconciliable con la contenida en el artículo $218^{\circ}$ ibidem que consagra el carácter civil de la Policía Nacional».

Se desprende también de este fallo que una cosa será una tensión entre normas constitucionales y otra diferente el caso de las antinomias constitucionales. La Corte se refirió a una teoría alemana que considera la posibilidad de que existan normas constitucionales inconstitucionales, para concluir que no tenía cabida en el proceso de conocimiento, si bien «está destinada a aplicarse sólo en aquellos casos extremos en los que la contradicción normativa impide al intérprete aplicar el principio general de armonización». Esta parece ser una excepción al principio de armonización concreta que posiblemente tenga desarrollos en el futuro.

\subsection{Salvamento de voto de la sentencia SU-047/99:}

$\square$ La constitución recoge datos de diversas corrientes ideológicas.

$\square$ La técnica de la ponderación pone en evidencia que de las normas constitucionales no es posible derivar una respuesta única sino múltiples.

\subsection{Sentencia T-425/95:}

$\square$ Las colisiones constitucionales deben solucionarse atendiendo al principio de eficacia.

$\square$ El intérprete debe maximizar cada norma.

$\square$ Los límites de los derechos que se armonizan deben ser proporcionales, es decir, deben ser los indispensables para permitir la máxima efectividad de los derechos en pugna.

$\square$ Los alcances de cada derecho en pugna se precisan en el caso concreto.

$\square$ No hay prelaciones abstractas de derechos.

\subsection{Sentencia T-575/95:}

$\square$ El principio de armonización impide que la efectividad de un derecho se ampare en la restricción o sacrificio de otro. 


\subsection{Sentencia T-622/95:}

$\square$ Los remedios que ordene un juez no pueden significar el sacrificio injusto de los derechos de otras personas.

\subsection{Salvamento de voto de la Sentencia C-075/97:}

En el juicio constitucional no es procedente establecer a priori una prevalencia abstracta de principios constitucionales enfrentados.

\subsection{Sentencia T-588/98:}

- Si los mismos objetivos pueden obtenerse a través de diferentes medios, el operador jurídico debe optar por la solución que permita el simultáneo ejercicio de derechos en aparente conflicto.

$\square \mathrm{O}$ bien puede ajustarse el único medio existente si resulta objetivamente insustituible. En este caso la posibilidad de armonización concreta se reduce.

\subsection{Sentencia T-801/98:}

- Se debe optar por la decisión que permita la coexistencia de derechos en conflicto.

La armonización debe atender a criterios de proporcionalidad, los cuales remiten a la comparación de dos variables relativas conciliables sólo en la situación concreta.

\subsection{Sentencia T-210/94:}

El intérprete debe garantizar el mayor radio de acción posible a los derechos en conflicto.

La restricción de los derechos encuentra su límite en el núcleo esencial de los derechos.

El fallador debe apreciar las circunstancias de tiempo, modo y lugar en que se ejercen los derechos para determinar la proporcionalidad de su ejercicio.

$\square$ Es desproporcionada toda decisión de afecte el núcleo esencial.

El justo ejercicio, la justa medida de un derecho está determinada por los efectos que sobre otros derechos tienen los medios empleados. 


\subsection{Sentencia C-444/95:}

La lógica formal debe ser corregida por el principio de armonización.

\section{Principio de efectividad de los derechos fundamentales.}

Este principio ha sido definido de la siguiente manera: «Siempre se debe preferir la interpretación que permita la armonización y la compatibilidad de los derechos sobre aquella que imponga un sacrificio excesivo a alguno de ellos» (C-473 de 1994). Según esta definición, el principio de efectividad se identifica con los principios de armonización y de proporcionalidad. Algunas consecuencias que ha derivado la jurisprudencia de este principio son las siguientes:

\subsection{Sentencia C- 531 de 1995 :}

En virtud de este principio, la ineficiencia de las autoridades no puede ser una razón válida para desconocer los derechos de los particulares.

\subsection{Sentencia T-500 de 1994:}

$\square$ Los derechos y el bienestar de las personas son la razón de ser de las autoridades.

$\square$ Las autoridades administrativas no deben esperar a que los ciudadanos instauren acciones judiciales o administrativas para poner en marcha las medidas que hagan efectivos los derechos de las personas.

\subsection{Sentencia T-290 de 1994:}

$\square$ La Constitución se inspira en la efectividad de los derechos, pues ellos fundamentan la legitimidad del orden jurídico, por ser esenciales a la dignidad de la persona, fin del orden jurídico universal.

\subsection{Sentencia T-533 de 1992:}

$\square$ El principio de efectividad de los derechos fundamentales, obliga al juez de tutela a definir, dentro del proceso, el medio más eficaz para 
promover su cumplimiento, máxime cuando la ley no lo contempla o lo hace de manera genérica.

\subsection{Sentencia T-068 de 1998:}

$\square$ La efectividad de los derechos se desarrolla con base en dos cualidades: la eficacia y la eficiencia administrativa. La primera relativa al cumplimiento de las determinaciones de la administración y la segunda relacionada con la elección de los medios más adecuados para el cumplimiento de los objetivos.

\section{Principio de conservación del derecho.}

Definido en la Sentencia C-466/97 de la siguiente manera: «los tribunales constitucionales deben siempre buscar preservar al máximo las disposiciones emanadas del legislador, en virtud del respeto al principio democrático. Por ello si una disposición admite una interpretación acorde con la Carta, es deber de esta Corte declararla exequible de manera condicionada, y no retirarla del ordenamiento".

Esta pauta de interpretación carece de sustento normativo explícito; sin embargo la Corte se apoya en la doctrina para explicar el sentido en que debe entenderse. En la sentencia C-100/96, por ejemplo, se cita a Raúl Canosa Usera (Interpretación Constitucional y fórmula política. Madrid: Centro de Estudios Constitucionales, 1988, p. 180). Se debe anotar que el principio de conservación del derecho va dirigido a la propia Corte Constitucional y normalmente se utiliza cuando se van a expedir sentencias de interpretación condicionada, aunque sirve también con frecuencia a los intereses de aquellos magistrados que salvan su voto en casos de inexequibilidad, como se verifica por ejemplo en la Sentencia C-065/97.

\subsection{Sentencia C-600A/95:}

$\square$ La Corte debe evitar el «desmantelamiento del orden jurídico».

$\square$ Son preferibles las decisiones que preserven normas en vez de las que anulan.

$\square$ No es razonable que la Corte declare inexequibles normas que fueron aprobadas como orgánicas pero que son propias de ley ordina- 
ria, porque la mayoría de las leyes orgánicas sirven para aprobar ley ordinaria. De otro lado, para asegurar el principio de competencia general de ley ordinaria no es indispensable anular la norma.

$\square$ En estos casos lo que debe hacer la Corte es declarar que las normas acusadas son ordinarias no obstante estar contenidas en ley orgánica.

La Constitución no prohibe que una misma ley contenga materias de ley orgánica y ordinaria, siempre que guarden conexidad temática.

$\square$ Las normas orgánicas territoriales pueden estar contenidas en diversas leyes y no necesariamente en un documento legal único.

$\square$ Si bien la Constitución se refiere a la «ley orgánica de ordenamiento territorial», la Corte prefiere hablar de «legislación orgánica de ordenamiento territorial».

Se debe anotar que en el caso de las leyes estatutarias, la Corte ha enfatizado sobre la inconveniencia de permitir al legislador regular aspectos propios de ley procesal u ordinaria en una ley de esta clase: "Permitir lo contrario sería tanto como admitir la petrificación de las normas procesales y la consecuente imposibilidad de contar con una administración de justicia seria, responsable, eficaz y diligente» (Sentencia C-037 de 1996). En apariencia no vemos razones para desechar la posibilidad de conservar normas ordinarias aprobadas en formato de ley estatutaria, declarando simplemente que se trata de disposiciones ordinarias.

\subsection{Sentencia C-405/98:}

- Se deben preservar al máximo las normas legales porque existe un deber de respetar el principio democrático.

$\square$ Por lo señalado anteriormente, se deduce que es un deber de la Corte dictar sentencias de exequibilidad condicionada.

\subsection{Salvamento de voto a la sentencia C-318/98:}

$\square$ Si una norma resulta exequible aplicada a ciertas hipótesis, la Corte no puede declararla inexequible.

$\square$ Pero el fallo debe diferenciar tales hipótesis e indicar con claridad las condiciones de vigencia de la norma legal. 


\subsection{Sentencia C-070/96:}

$\square$ No es posible excluir una norma cuando existe por lo menos una interpretación conciliable con la Constitución.

$\checkmark$ Este principio maximiza la eficacia de la actuación estatal.

$\square$ Existe una presunción de legalidad democrática.

$\square$ El juez debe tener en cuenta el costo social e institucional de declarar la inconstitucionalidad de una norma.

$\square$ La total ineficacia de un precepto no hace que éste devenga inconstitucional (validez no es igual a eficacia).

Las normas acusadas de inconstitucionalidad en razón de su ineficacia deben subsistir.

En este fallo la Corte afirmó que «la ineficacia de la prevención en materia penal no torna inconstitucional la disposición acusada. En el ordenamiento jurídico pueden subsistir normas ineficaces que, por esta sola circunstancia fáctica, no deben ser declaradas inexequibles». La Corte ha manejado confusamente el problema de la ineficacia como fundamento de una declaración de inconstitucionalidad (Cfr. Infra Sentencia C-499 de 1998).

\subsection{Sentencia C-499/98:}

$\square$ La Corte identifica el principio de conservación del derecho con el de interpretación de la ley conforme a la Constitución.

$\square$ Deben salvaguardarse algunos de los efectos jurídicos de las disposiciones demandadas.

\subsection{Sentencia C-468/97:}

Los tratados deben ser aprobados mediante ley aprobatoria de tratados.

L Las leyes aprobatorias de tratados sólo pueden contener tratados.

Las leyes aprobatorias no pueden contener instrumentos jurídicos de otra naturaleza.

El Congreso no puede utilizar la forma jurídica de ley aprobatoria de tratado para regular otros temas.

El legislador no es libre de escoger el tipo de leyes porque la Constitución predetermina ciertas formas jurídicas. 
$\square$ El debate legislativo en la aprobación de tratados es reducido, pues el legislador solo puede aprobar o desaprobar el convenio o las cláusulas del convenio.

$\square$ Las recomendaciones de la OIT, por su parte, no son tratados.

$\square$ Al dar trámite de ley aprobatoria a una recomendación de la OIT, el legislador limitó sus posibilidades de introducir modificaciones al texto.

El lenguaje de las recomendaciones es exhortativo, no normativo.

En estos casos no opera el principio de conservación del derecho porque no hay derecho que conservar.

\subsection{Sentencia C-320/97:}

$\square$ Los defectos de lenguaje en las normas no son causal de inconstitucionalidad.

$\square$ En estos casos el juez debe ajustar el lenguaje legal a los principios $y$ valores constitucionales.

\subsection{Salvamento de voto a la Sentencia C-152/97:}

El principio de conservación del derecho tiene una mayor intensidad en los casos en que la disposición legislativa busca dar cumplimiento a mandatos constitucionales.

$\square$ Es más imperiosa la modalidad de sentencia condicional en estos casos.

\subsection{Sentencia C-324/97:}

$\square$ En materia de objeciones presidenciales no es aplicable el principio de conservación del derecho. $\mathrm{O}$ bien, el principio tiene menor peso en estos casos.

$\square$ El principio de conservación sólo opera en relación con normas vigentes.

$\square$ Se respeta mejor la seguridad jurídica y el principio democrático cuando la Corte declara la inexequibilidad de normas objetadas porque de esta manera abre al Congreso la posibilidad de rehacer e integrar los artículos afectados. 
En esta sentencia la Corte fue explícita en afirmar que el principio de conservación no opera en objeciones presidenciales; sin embargo, con anterioridad había aplicado el supuesto contrario, en el caso del estudio de objeciones presidenciales en la Sentencia C-360 de 1996.

\section{Principio de interpretación conforme a la Constitución}

\subsection{Salvamento de voto a la Sentencia C-075/97:}

$\square$ Este principio impone al juez constitucional el imperativo de indagar por las varias interpretaciones posibles de una disposición legal, antes de proceder a expulsarla del ordenamiento por encontrar que una de ellas contraviene lo dispuesto en la Constitución.

Si de las distintas alternativas, al menos una se aviene a los mandatos de la Carta, el juez debe conservarla y proceder a descartar sólo aquella que no cumple tal requisito.

$\square$ Sólo procede la declaración de exequibilidad de una norma legal cuando resulte francamente imposible encontrar una interpretación que permita su adecuación a los mandatos constitucionales.

\subsection{Sentencia T-397 de 1997:}

$\square$ Puede ocurrir que una norma expedida bajo la vigencia de la Constitución de 1886, ajustada a sus mandatos, contraríe las normas de la actual Constitución si se le interpreta literalmente.

$\square$ Ante esta situación al juez que le corresponde velar por la supremacía y la cualidad integral de la Constitución, no le queda otro camino que asegurar la preservación de los derechos, principios y valores, y hacer una interpretación de la norma conforme a la Constitución.

$\square$ Si es posible dejar de aplicar una norma jurídica por ser manifiestamente contraria a la Constitución, con mayor razón, en aras de asegurar la preservación del derecho, es procedente que el juez constitucional pueda hacer una interpretación conforme con la Constitución, sin necesidad de no aplicar la norma, dado que no se presenta la situación de incompatibilidad de dos disposiciones que no puedan ser aplicadas y subsistir al mismo tiempo.

De esta manera, se produce una especie de actualización de la norma frente a la nueva Constitución, o dicho de otro modo, una es- 
pecie de incorporación de los mandatos constitucionales a dicha norma.

\subsection{Aclaración de voto a la Sentencia $\mathrm{N}^{\circ} \mathrm{C}-174 / 96$ :}

Los jueces de la República deben aplicar, en la resolución de los casos concretos, el principio de interpretación conforme a la constitución de las normas demandadas, entre tanto el legislador corrige las disposiciones que no han sido declaradas inexequibles pero que pueden generan efectos inconstitucionales.

\subsection{Sentencia T-243 de 1998:}

- Con arreglo al artículo $4^{\circ}$ de la Constitución, que es norma de normas, quienes tienen la atribución de aplicar las de la ley deben buscar, propiciar y preferir la interpretación y aplicación de aquellas que mejor se ajusten a los mandatos superiores.

El intérprete debe procurar que, en caso de duda, el entendimiento seleccionado de una norma no implique pugna o ruptura con el sistema jurídico que la Carta Política instaura.

\subsection{Sentencia T-180 de 1996:}

La disposición interna universitaria que pueda afectar derechos y libertades constitucionalmente reconocidos, debe someterse a un juicio de constitucionalidad a fin de garantizar que su aplicación esté conforme con la Constitución

9. Principio del efecto útil de las normas.

El principio del efecto útil está recogido en el artículo $1620^{\circ}$ del Código Civil, según el cual «El sentido en que una cláusula puede producir algún efecto, deberá preferirse a aquel en que no sea capaz de producir efecto alguno». De allí fue tomado por la Corte para ser incorporado a la jurisprudencia constitucional. Las pautas que ha dado la Corte a este respecto son las siguientes: 


\subsection{Sentencia T-01/92:}

$\square$ Entre dos posibles sentidos de un precepto, uno de los cuales produce consecuencias jurídicas y el otro a nada conduce, debe preferirse el primero.

$\square$ Se deben rechazar hipótesis carentes de sentido.

\subsection{Salvamento de voto a la Sentencia C-557 de 1992:}

$\square$ Deben rechazarse interpretaciones normativas por las consecuencias absurdas a las que conduce.

Se deben rechazar las interpretaciones inútiles.

La interpretación con efecto útil es un principio general de derecho positivizado y criterio auxiliar de conformidad con el artículo $230^{\circ}$ de la Carta.

\subsection{Sentencia C-009/94:}

$\square \mathrm{El}$ artículo $53^{\circ}$ de la Constitución no debe interpretarse en el sentido de hacer inútil el alcance del artículo $39^{\circ}$ que garantiza el ejercicio del derecho a la negociación colectiva: se pueden conciliar derechos adquiridos con la posibilidad de la negociación colectiva.

En esta misma ocasión dijo la Corte: «El efecto útil que debe producir la norma del artículo $53^{\circ}$, aunado a la conciliación entre los derechos adquiridos por los trabajadores con el derecho de negociación colectiva, permite colegir, que en una nueva convención colectiva puedan modificarse, sustituirse, e inclusive eliminarse derechos, que antes reconocía una convención, siempre que la nueva situación en que se ubique a los trabajadores, en términos reales u objetivos, implique el reconocimiento de derechos que sean iguales o superiores a los obtenidos anteriormente, o que sea imperiosa su revisión, debido a circunstancias excepcionales e imprevisibles».

\subsection{Sentencia C-145/94:}

No debe suponerse que las normas constitucionales son superfluas. $\square$ Debe preferirse la interpretación que confiere pleno efecto a la Constitución. 


\subsection{Sentencia C-399/95:}

$\square$ Se debe preferir la interpretación que confiere un sentido a todas las cláusulas de la Constitución sobre aquella que resta eficacia a determinados acápites del texto constitucional.

\subsection{Sentencia C-473/94:}

$\square$ No puede afirmarse que la palabra "esenciales» del Art. $56^{\circ}$ de la Constitución carece de eficacia normativa; por el efecto útil debe interpretarse que tal palabra significa que existen servicios públicos que son esenciales y otros que no lo son: se buscó ampliar el campo del derecho de huelga, bastante limitado en el pasado.

$\square$ La palabra «esenciales» tiene el efecto útil de reducir el ámbito de restricción del derecho de huelga

\subsection{Sentencia C-600A/95:}

$\square$ En general la distribución de competencias entre la nación y las entidades territoriales -tanto normativas como no normativas- es materia de ley orgánica.

$\square$ Pero no toda asignación de competencias entre la nación y las entidades territoriales requieren ley orgánica.

$\square$ La Constitución a veces distribuye directamente ciertas competencias de suerte que la ley ordinaria puede reglamentarla; o bien una ley orgánica puede dar pautas de distribución y luego la ley ordinaria dar competencias específicas con base en esa ley.

$\square$ No puede haber ley que distribuya sin norma constitucional o ley orgánica previa.

$\square$ El artículo $288^{\circ}$ tiene un contenido autónomo del artículo $151^{\circ}$ de la Constitución. Esa es una interpretación útil de tales normas.

\subsection{Sentencia C-499/98:}

$\square$ Si una interpretación conforme a la Constitución le resta eficacia jurídica a una norma, lo procedente es declarar la inexequibilidad.

$\square$ Debe preferirse la inexequibilidad a la exequibilidad condicionada si esta última hace ineficaz la norma. 
El tratamiento de este principio resulta contradictorio con otras opiniones de la Corte. Una norma que carece de eficacia se contradice con el principio del efecto útil de la norma, según el fallo en comento; pero en la Sentencia C-070/96 la misma Corporación había sostenido que la total ineficacia de un precepto no hace que éste devenga inconstitucional por cuanto validez no es igual a eficacia.

\subsection{Aclaración de voto a la Sentencia C-194/95:}

Las inhabilidades se deben interpretar de conformidad con el principio del efecto útil, como en el caso del artículo $179^{\circ}$ de la Constitución.

\subsection{Salvamento de voto a la sentencia C-317/98:}

El principio, en aras de la utilidad, no puede llegar al extremo de atribuir a una cláusula constitucional un sentido contrario al que se desprende de su sentido natural.

\section{Principio de interpretación razonable.}

Este principio tampoco encuentra sustento normativo expreso en la C.c. y su significado y función se define a partir de las siguientes pautas:

\subsection{Sentencia T-322 de 1996:}

La razonabilidad indica que un juicio está conforme a la prudencia, a la justicia y a la equidad.

$\square$ La razonabilidad se proyecta sobre casos concretos.

Implica una coherencia externa con los supuestos fácticos.

$\square$ Este principio supera la tradicional racionalidad porque ésta exige una coherencia interna, una lógica formal, mientras que en lo razonable la coherencia es externa.

- En lo razonable cobra fuerza la relación de lo constitucionalmente admisible.

La razonabilidad atiende a la finalidad de la norma y a su efecto útil.

$\square$ La razonabilidad es propia del Estado democrático. 
Cuando dos hipótesis son racionales la preferencia debe inclinarse en favor de la razonable.

La razonabilidad privilegia el método finalístico y el sistemático.

$\checkmark$ La razonabilidad privilegia el principio de favorabilidad penal y el principio pro operario.

\subsection{Salvamento de voto a la Sentencia T-142/94:}

La razonabilidad es una idea asociada al principio de la efectividad.

$\square$ No se deben fosilizar los postulados normativos.

El juez debe buscar la respuesta a los problemas.

No se debe paralizar el progreso de la dogmática y se debe tener en cuenta que muchas soluciones están por fuera de la ley.

$\square$ La ley no debería aplicarse cuando produce consecuencias indeseadas.

\section{Principio de interpretación sistemática.}

La Corte identifica el método de interpretación sistemática con un principio que llevaría el mismo nombre.

\subsection{Sentencia C-040/93:}

Un principio fundamental de hermenéutica es el de interpretar sistemáticamente un conjunto normativo.

\section{Principio de interés superior del menor.}

Para efectos de la protección constitucional, el concepto de niños incluye a los adolescentes y a todos aquellos que no han cumplido la mayoría de edad (Sentencia T-298 de 1994). Es este un principio derivado directamente del artículo $44^{\circ}$ de la C.c., cuyos efectos son los siguientes:

\subsection{Sentencia T-298/94:}

Los niños tienen privilegio constitucional.

Se debe poner a salvo en cualquier situación el interés del niño.

Existe un tratamiento de favor a los niños en cualquier proceso social, 
Circunstancias de debilidad anormales de un menor ameritan tratos más especiales todavía: máxima exigencia de protección.

$\square$ El privilegio de los menores produce efectos en diversos planos.

Las condiciones físicas y mentales del menor requieren protección especial.

Protección especial significa que una situación de debilidad justifica tratos que normalmente sería discriminatorios.

$\square$ Dentro del gasto público social tienen prioridad las asignaciones dirigidas a atender derechos de prestación de los menores.

Todas las personas tienen legitimidad para exigir el cumplimiento de los derechos de los menores y solicitar sanciones.

Los conflictos de derechos que comprometan a un menor se resuelven en favor de éste.

El trato especial del niño es un «ensayo de igualación» que realiza el constituyente.

$\square$ Como el niño no sabe, ni puede pedir, la Constitución autoriza que todos pidan por él, y como el niño no puede imponer sus derechos, la Constitución define directamente su prevalencia.

$\square$ La salud se ha señalado expresamente como derecho fundamental para los menores (Cfr. También la Sentencia T-727 de 1998).

\subsection{Sentencia T-556/98:}

$\square$ Los menores tienen una caracterización jurídica específica.

En estos casos, existen derechos prevalentes que ameritan un trato de prelación.

Siempre debe existir defensa ante abusos sobre menores.

\subsection{Sentencia SU-225/98:}

Los derechos fundamentales de carácter prestacional tienen un núcleo fundamental mínimo exigible por tutela y un zona complementaria definida por los órganos políticos atendiendo a la disponibilidad de recursos.

Los derechos de los niños son derechos prestacionales fundamentales.

Otras sentencias en las cuales la Corte se refiere a este principio son las siguientes: T-408 del 14 de septiembre de 1995 y T-514 del 21 de septiembre de 1998. 


\section{Principio de la unidad constitucional.}

Concreta las aspiraciones de unidad y coherencia del derecho, pero proyectadas al nivel de las normas constitucionales. La Constitución pretende ser un orden unitario de la vida política y si esto es así, la interpretación debería generar un efecto integrador, es decir, propiciar soluciones que refuercen la unidad del país. Este principio, bastante recurrido en la jurisprudencia, exige buscar conexión de sentido entre preceptos y no hacer interpretaciones aisladas. «La idea de unidad de la constitución parte de que la constitución no es un conglomerado de normas jurídicas yuxtapuestas las unas a las otras, sino que está sostenida por una concepción, por una idea, que intenta ser un todo cerrado del orden de la vida de la comunidad [...]” ${ }^{7}$.

Este principio está asociado al de armonización porque implica la necesidad de poner en concordancia unas normas con otras. Se trata de equilibrar la aplicación de las normas que están en una relación de tensión en el caso concreto, sin negar eficacia o inaplicar una en beneficio de la otra. Se trata pues de una exigencia de concordancia práctica, que obliga a solucionar los problemas interpretativos de manera que las normas relacionadas en el caso conserven su contenido.

\subsection{Sentencias T-425/95 y T-575 de 1995 :}

Debe reconocerse que hay colisiones entre normas constitucionales.

$\square$ Las colisiones se resuelven buscando la óptima eficacia de las normas encontradas.

La interpretación debe proyectarse sobre un todo armónico y coherente.

$\square$ No son dables las interpretaciones aisladas o contradictorias.

\subsection{Sentencia C-255/97:}

$\square$ El contenido de una norma superior no debe agotar el contenido de otras disposiciones constitucionales. 


\section{Principio del menor daño constitucional.}

Carece de sustento constitucional explícito. Las pautas para su aplicación son las siguientes:

\subsection{Sentencia T-458/97:}

$\checkmark$ La tarea del juez en un estado social es la de promover y garantizar los derechos.

Cada decisión debe ser la realización de un bien jurídico.

A veces el juez se encuentra en una "circunstancia trágica": las decisiones jurídicamente admisibles tendrán, necesariamente, todas ellas, un efecto nocivo.

$\square$ En estos casos el juez debe dar curso a la decisión que tenga el menor costo constitucional.

$\square$ Se debe escoger la decisión que produzca menor daño desde la Constitución.

\section{Principio pro favor libertatis o favor de libertad.}

Se basa en la idea de la fuerza expansiva del derecho a la libertad y de la especial protección constitucional de que goza aun en estados de excepción.

\subsection{Sentencia C-179/94:}

Tiene operancia para casos de estados de excepción.

Existen núcleos esenciales de los derechos, es decir, elementos sin los cuales el derecho deja de ser lo que es.

$\square$ No existen nociones anticipadas sobre el núcleo esencial de un derecho específico. Irremediablemente es tarea del intérprete decir en casos concretos si se presenta una vulneración del núcleo esencial.

En casos dudosos, el intérprete debe tener presente que la restricción es lo excepcional y lo excepcional debe justificarse sin dejar margen de duda.

El intérprete debe inclinarse en favor de la libertad. 


\subsection{Sentencia C-445/98:}

$\square$ De la fuerza expansiva del derecho a la libertad se deriva el principio pro libertate.

Entre dos interpretaciones, una de las cuales reduce y la otra amplifica el derecho, debe preferirse la segunda.

\section{Principio de proporcionalidad.}

La Corte deduce la existencia de este principio de varias normas constitucionales, así: artículos $1^{\circ}$ (Estado social de derecho, principio de dignidad humana), $2^{\circ}$ (principio de efectividad de los principios, derechos y deberes consagrados en la Constitución), $5^{\circ}$ (reconocimiento de los derechos inalienables de la persona), $6^{\circ}$ (responsabilidad por extralimitación de las funciones públicas), $11^{\circ}$ (prohibición de la pena de muerte), $12^{\circ}$ (prohibición de tratos o penas crueles, inhumanos o degradantes), $13^{\circ}$ (principio de igualdad) y $214^{\circ}$ de la Constitución (proporcionalidad de las medidas excepcionales).

\subsection{Sentencia C-070 de 1996 :}

$\square$ La proporcionalidad alude a una prohibición de excesos.

Es el corolario constitucional del principio legal de la antijuridicidad.

- Presupone la ponderación de bienes jurídicos constitucionales.

Tal ponderación se traduce en un juicio de proporcionalidad de los medios.

- Sirve para delimitar y concretar derechos constitucionales.

Exhibe una naturaleza diferencial: admite diversas configuraciones legislativas dependiendo de la materia.

- Sólo la restricción excesiva e imprevisible de los mismos implica la ilegitimidad del medio escogido para la realización de los fines constitucionales.

Entre mayor sea la intensidad de la restricción a un derecho, mayor será la urgencia y la necesidad exigidas como condición para el ejercicio legítimo de la facultad legal de restringir. 


\subsection{Sentencia T-425 de 1995:}

$\square$ La proporcionalidad se deduce del deber de respetar los derechos ajenos y no abusar de los propios.

$\checkmark$ Es un límite al ejercicio de los derechos.

Los límites trazados a los derechos deben ser los indispensables para que se cumpla el principio de la máxima efectividad de los derechos.

$\checkmark$ La proporcionalidad implica una comparación de dos variables relativas en un caso.

La limitación proporcional de los derechos requiere tomarse "en serio» la finalidad social del estado de garantizar la efectividad de los derechos.

Este principio impide restricciones injustificadas.

Es el juez quien hace la ponderación en colisiones de derechos constitucionales.

- Se debe buscar un equilibrio práctico de las necesidades de los titulares de los derechos.

16.3. Sentencias $T-422 / 92, \mathrm{C}-530 / 93, \mathrm{~T}-230 / 94, \mathrm{~T}-288 / 95$ y C-022/96:

$\square$ La idea de proporcionalidad sirve para determinar si un trato diferente o una restricción de un derecho se ajustan a la Carta.

Cuando dos principios entran en colisión, corresponde al juez constitucional determinar si la reducción de uno de ellos es proporcionada, a la luz de la importancia del principio afectado.

$\checkmark$ Debe el juez, en primer lugar, determinar si el trato diferente y la restricción a los derechos constitucionales son «adecuados» para lograr el fin perseguido.

$\square$ Debe el juez, en segundo lugar, determinar si son "necesarios", en el sentido de que no exista otro medio menos oneroso en términos de sacrificio de otros principios constitucionales para alcanzar el fin perseguido $y$,

Debe el juez, finalmente, determinar si las restricciones son "proporcionadas stricto sensum, esto es, verificar que no se sacrifiquen valores y principios que tengan un mayor peso que el principio que se pretende satisfacer. 


\subsection{Sentencia C-093/96:}

$\square$ La restricción legal para el ejercicio de un derecho debe tener una finalidad constitucional.

La proporcionalidad debe hacer efectivo y posible el derecho.

$\checkmark$ La proporcionalidad atiende al medio empleado para el efecto y a su idoneidad para lograr el fin propuesto.

$\square$ El sacrificio que comporta la medida no debe superar el beneficio que se obtiene.

\section{Principio de prevalencia de tratados internacionales.}

Este principio tiene fundamento expreso en el artículo $93^{\circ}$ de la Constitución y se debe entender según las siguientes directrices:

\subsection{Sentencia C-179 de 1994:}

$\square$ El alcance del artículo $93^{\circ}$ constitucional es limitado.

Tal artículo no se refiere a todos los derechos humanos consagrados en los todos los tratados y convenios.

- Sólo se refiere a éstos cuando tales instrumentos internacionales prohiben la limitación de derechos en los estados de excepción.

La prevalencia o superioridad de los tratados y convenios internacionales en el orden interno requiere dos supuestos: el reconocimiento de un derecho humano y, de otra parte, que sea de aquellos cuya limitación se prohiba durante los estados de excepción.

$\square$ El artículo $93^{\circ}$ debe ser necesariamente interpretado en relación con el artículo 214-2 de la C.c.

$\checkmark$ Una tercera condición para que esos tratados sean prevalentes es que no contrarín la Constitución, de manera que sólo deberán acatarse aquéllos que no vulneren sus preceptos.

\section{Principio de la presunción de racionalidad del legislador.}

Tampoco tiene fundamento directo en norma constitucional alguna, pero la jurisprudencia lo considera una norma implícita: 
18.1. Sentencia C-112/96:

Todo orden jurídico presupone una lógica interna.

$\square$ Esa lógica deriva del supuesto de la racionalidad del legislador.

$\checkmark$ Se debe asumir que el legislador no se contradice.

El intérprete debe asumir que el derecho es sistemático y coherente. Es ésta "una pauta o directriz interpretativa».

$\checkmark$ El intérprete debe analizar sistemáticamente; debe correlacionar; debe excluir interpretaciones absurdas.

$\square$ El juez debe aceptar que el derecho es un sistema y debe aceptar un principio de coherencia jurídica e institucional.

19. Principio de decisión normativa de las mayorías políticas.

Llamado también principio la libertad de configuración política del legislador. Ha dicho la Corte Constitucional a este respecto:

\subsection{Sentencia C-109/95:}

La ley puede regular en forma diversa los distintos asuntos.

El poder legislativo es el representante en cada momento histórico de la soberanía popular.

- Al legislador corresponde establecer las regulaciones jurídicas según las específicas situaciones sociales de cada momento.

El legislador no tiene una discrecionalidad absoluta, pues debe respetar la Constitución, puesto que ella es norma de normas (CP Art. $4^{\circ}$ ).

- En ciertos casos, la Corte Constitucional puede formular sentencias en las cuales integra el ordenamiento jurídico mientras que el legislador se ocupa del tema.

20. Principio de libre iniciativa legislativa.

Consagrado en el artículo $154^{\circ}$ de la C.c. es interpretado de la siguiente manera: 


\subsection{Sentencia C-360/96:}

$\square$ Prevalece el principio democrático, la soberanía popular, la participación ciudadana en el ejercicio del poder político y la cláusula general de competencia.

La regla general establecida en el artículo $154^{\circ}$ de la Carta que consagra el principio de la libre iniciativa, permite concluir que, con excepción de las específicas materias reservadas por la propia Constitución, la directriz general, aplicable a la iniciativa legislativa de los miembros del congreso, es la de la plena libertad.

$\square$ Las excepciones de la Constitución son de interpretación restrictiva y no pueden ser ampliadas

\subsection{Sentencia C- 490 de 1994 :}

$\square$ No existe en la Constitución una interdicción general aplicable a la iniciativa de los miembros del Congreso para presentar proyectos de ley que comporten gasto público.

\section{Principio de mensurabilidad.}

No tiene fundamento normativo expreso en la C.c., si bien la jurisprudencia lo deriva de otros principios básicos, como la cláusula del estado social de derecho:

\subsection{Sentencia C-318 de 1995:}

Las potestades discrecionales se encuentran sometidas al principio de mensurabilidad.

En ningún caso la potestad discrecional puede constituirse como un poder indefinido o ilimitado.

- En el Estado social de derecho las competencias son regladas y el margen de discrecionalidad de los agentes públicos debe ejercitarse dentro de la filosofía de los valores y principios materiales de la nueva Constitución.

$\square$ La potestad discrecional exige definición de su ámbito de acción, los fines a cumplir y la forma en la cual se debe desplegar la conducta mencionada y de las circunstancias teleológicas y materiales. 


\section{Principio de participación democrática.}

Consagrado en varias normas constitucionales, entre ellas el preámbulo y el artículo $2^{\circ}$.

\subsection{Sentencia C-021 de 1996:}

$\square$ La participación es un principio constitucional que no se agota en el terreno de las decisiones políticas, sino que se extiende a los más diversos campos.

$\square$ Es clara la voluntad del Constituyente en el sentido de facilitar, estimular y aun hacer forzosa, en algunos casos, la presencia activa de los gobernados.

$\square$ La democracia participativa procura otorgar al ciudadano la certidumbre de que no será excluido del debate, ni de la resolución, ni de los procesos políticos.

$\square$ El ciudadano es parte activa en las determinaciones de carácter público.

$\square$ El tránsito de una democracia representativa a una participativa implica un nuevo modelo que incorpora a los mecanismos tradicionales, instituciones de democracia directa.

En las Sentencias T-03 del 11 de mayo de 1992 y C-454 de 1993 dijo la Corte que: «el principio de la participación se constituye en elemento esencial dentro de la filosofía política que inspira la Carta y en sustento innegable de las nuevas instituciones». $Y$ ha dicho también en la Sentencia T-418/ 1993 que «en la democracia representativa también hay participación [...]. Pero la democracia no tiene que ser siempre la decisión directa y personal de los asociados sobre todo asunto, sin lugar de ser representados".

\section{Principio de universalidad.}

La Corte Constitucional acuñó el principio de universalidad para fijar las condiciones a partir de las cuales un tribunal puede apartarse de sus precedentes. Un caso particularmente polémico es el de la Sentencia SU-047 de 1999, mediante la cual se rectificó, en sede de tutela, la doctrina sobre inviolabilidad parlamentaria que se había asentado en las sentencias C-222 de 1996 y C-245 de 1996. Veamos: 


\subsection{Sentencia SU-047 de 1999:}

$\square \mathrm{El}$ respeto a los precedentes cumple funciones esenciales en los ordenamientos jurídicos.

$\square$ Todo tribunal, y en especial el juez constitucional, debe ser consistente con sus decisiones previas, por cuatro razones:

a. Consideraciones de seguridad jurídica y de coherencia del sistema jurídico: las normas deben tener un significado estable; las decisiones de los jueces deben ser razonablemente previsibles.

b. La libertad ciudadana y el desarrollo económico: una caprichosa variación de los criterios de interpretación pone en riesgo la libertad individual, así como la estabilidad de los contratos y de las transacciones económicas.

c. El principio de igualdad, puesto que no es justo que casos iguales sean resueltos de manera distinta por un mismo juez.

d. Finalmente, como un mecanismo de control de la propia actividad judicial, pues el respeto al precedente impone a los jueces una mínima racionalidad y universalidad, ya que los obliga a decidir el problema que les es planteado de una manera que estarían dispuestos a aceptar en otro caso diferente pero que presente caracteres análogos.

$\square$ Pero el precedente no debe ser sacralizado.

$\square$ No se debe petrificar el ordenamiento jurídico.

$\square$ No puede provocar injusticias en la decisión de un caso.

$\square$ Las equivocaciones del pasado no tienen porqué justificar las equivocaciones del futuro.

$\square$ Una interpretación puede haber sido útil pero su aplicación puede provocar consecuencias inesperadas e inaceptables en casos similares.

A veces es irrazonable adherir a la viejas hermenéuticas.

$\square$ Todo sistema jurídico presenta una tensión permanente entre la búsqueda de la seguridad jurídica y la realización de la justicia material del caso concreto.

$\square$ Un juez puede distanciarse de sus propios precedentes.

$\square$ Un funcionario judicial, en ejercicio de su autonomía interpretativa, puede modificar, aunque no de manera caprichosa, su entendimiento de las disposiciones legales y apartarse de sus decisiones previas.

$\square$ Incluso en los sistemas del Common Law, el principio del «stare 
decisis» o estarse a lo resuelto en casos anteriores, no es absoluto: los jueces pueden apartarse de un precedente, con el fin de precisar, corregir o modificar una línea jurisprudencial.

La modificación del precedente sólo puede ser llevado a cabo por la propia corporación judicial que lo formuló.

$\square$ Corresponde a la Corte Constitucional modificar las doctrinas constitucionales vinculantes que haya desarrollado en sus distintos fallos.

\subsection{Salvamento de voto de la sentencia SU-047/99 (Dr. Eduardo Cifuentes Muñoz):}

El precedente es un requisito de la interpretación constitucional.

- Hoy día se centra la atención del precedente en su relación con el principio de universalidad fundado en el primer imperativo categórico kantiano que dice "haz sólo aquello que al mismo tiempo puedas querer se convierta en ley universal".

$\square$ El juez sólo debe adoptar decisiones que en el futuro esté dispuesto a aplicar a casos similares.

$\square$ Cuando hay varias elecciones interpretativas, la decisión solo puede ser controlada por el principio de universalidad.

$\square \mathrm{El}$ respeto al precedente se encuentra íntimamente ligado a esto: los jueces deben fundamentar sus decisiones, no en criterios ad-hoc, caprichosos y coyunturales, sino con base en un principio general o una regla universal que han aceptado en casos anteriores, o que estarían dispuestos a aplicar en casos semejantes en el futuro.

$\square$ El juez tiene el deber mínimo de precisar la regla general o el principio que sirve de base a su decisión concreta.

$\square$ Existe una exigencia de universalidad de la argumentación jurídica, que es el requisito mínimo de racionalidad que debe tener una decisión judicial.

$\square$ Los jueces deben decidir sus casos con base en "principios neutrales y generales».

$\square$ Se deben decidir de manera similar los casos iguales.

$\square$ La existencia de una ratio decidendi en una sentencia es lo único que legitima en una democracia el enorme poder que tienen los jueces -funcionarios no electos- de decidir sobre la libertad, los derechos y los bienes de las otras personas. 
Todo cambio de jurisprudencia debe someterse al siguiente test. (1) que los jueces no actúen de manera coyuntural; (2) que las razones jurídicas que sirvieron para afirmar una determinada doctrina hayan demostrado su incompatibilidad con la comprensión actual del orden constitucional, porque, por ejemplo, el paso del tiempo las puede haber convertido en obsoletas o anacrónicas; (3) que exista un nuevo argumento que no hubiera sido discutido al momento de sentar la doctrina constitucional convertida en precedente y que éste resulte suficientemente convincente como para saldar las dudas sobre los verdaderos intereses de la corporación; (4) que el efecto benéfico del cambio de doctrina constitucional sea nítidamente superior al daño -en términos de legitimidad de la corporación y de seguridad jurídica- que produce el mencionado cambio.

\subsection{Sentencia C-400 de 1998:}

$\square$ Un tribunal puede apartarse de un precedente cuando considere necesario hacerlo.

$\square$ El tribunal tiene la carga de argumentación y aportar las razones que justifican el apartamiento.

- Se debe estructurar una nueva respuesta al problema planteado.

No basta que el tribunal considere que la interpretación actual es un poco mejor que la anterior.

$\square$ Para que un cambio jurisprudencial no sea arbitrario es necesario que el tribunal aporte razones que sean de un peso y una fuerza tales que, en el caso concreto, primen no sólo sobre los criterios que sirvieron de base a la decisión en el pasado sino, además, sobre las consideraciones de seguridad jurídica e igualdad que fundamentan el principio esencial del respeto del precedente en un Estado de derecho.

\section{Principio de racionalidad.}

Este principio normalmente aparece asociado al de razonabilidad en la jurisprudencia de la Corte: 


\subsection{Sentencias C-530 de 1993 y T-445 de 1994:}

La razonabilidad hace relación a que un juicio, raciocinio o idea esté conforme con la prudencia, la justicia o la equidad que rigen para el caso concreto. Es decir, cuando se justifica una acción o expresión de una idea, juicio o raciocinio por su conveniencia o necesidad.

$\square$ La racionalidad, en cambio, expresa el ejercicio de la razón como regla y medida de los actos humanos. Es simplemente, producto de la esencia racional del ser humano.

$\square$ Es posible afirmar que no es improbable que se presente la eventualidad de que un trato desigual "racional» -el supuesto de hecho, el trato desigual y la finalidad sean coherentes entre sí- no sea «razonable», porque la finalidad perseguida no es constitucionalmente admisible.

- Tampoco cabe desechar que unos supuestos de hecho distintos con una estructura razonable sea objeto de una diferenciación irracional.

\subsection{Salvamento de voto a la Sentencia T-561/93:}

$\square$ La racionalidad constitucional constituye una garantía de los derechos fundamentales y debe ser respetada incluso en aquellos casos en los cuales la aplicación del derecho constituye un inconveniente coyuntural.

$\square$ Pasar por encima de los procedimientos jurídicos, para lograr un hipotético beneficio social posterior, es ajeno a todo principio y valor constitucional y, por lo tanto, debe ser rechazado por la Corte Constitucional.

\section{Principio de razón suficiente.}

Sin fundamento normativo expreso. Dice la Corte Constitucional:

\subsection{Sentencia C-428 de 1997:}

La igualdad busca un tratamiento igual para casos análogos y diferente para situaciones cuyas características son distintas.

La existencia de la igualdad no limita la posibilidad de que pueda darse un tratamiento diferente para hechos que se encuentran cobi- 
jados bajo una misma premisa, siempre que la diferencia esté amparada por una razón clara y lógica que la convalide y que la doctrina constitucional ha denominado "principio de razón suficiente».

$\square$ Por ello, el establecer formas de diferenciación y tratamientos distintos no necesariamente conduce a una discriminación, pues a ésta sólo se llega cuando la diferencia no es el resultado de una justificación razonable y lógica.

\section{Principio de prevalencia de la justicia material.}

Un principio bastante recurrido en la jurisprudencia reciente. A veces se confunde con el principio de prevalencia del derecho sustancial.

\subsection{Sentencia T- 058 de 1995:}

$\square$ La prevalencia de la justicia material sobre los procedimientos tiene la naturaleza de un principio y, en consecuencia, su relevancia sólo puede ser el resultado de un trabajo de sopesamiento con otros principios y reglas.

$\square$ La prevalencia absoluta de la justicia material es insostenible teóricamente e impracticable judicialmente.

$\square$ Cuando la justicia material entra en conflicto con otros principios como el de certeza, seguridad y objetividad jurídica, la solución a dicho conflicto debe resultar del análisis fáctico que se plantea ante el juez de tutela.

$\square$ Existen casos en los cuales la aplicación directa y estricta de la norma contemplada, conduce a un resultado odioso o contraproducente que debe ser remediado mediante una interpretación que de prioridad a consideraciones de tipo material.

\subsection{Sentencia T-429 de 1994:}

$\square$ El principio de justicia material se opone a la aplicación formal y mecánica de la ley en la definición de una determinada situación jurídica.

$\square$ Exige, por el contrario, una preocupación por las consecuencias de la decisión y por la persona que es su destinataria.

$\square$ Las decisiones de los jueces deben significar una efectiva concreción de los principios, valores y derechos constitucionales. 


\section{Principio de prevalencia de la realidad.}

Tiene fundamento expreso en el artículo $53^{\circ}$ de la C.c. que alude a la primacía de la realidad sobre las formalidades establecidas por los sujetos de las relaciones laborales.

\subsection{Sentencia T-286 de 1994:}

Las normas de la Constitución relativas al tema laboral deben entenderse y aplicarse teniendo en cuenta que la vigencia efectiva de los derechos laborales exige la eliminación de mecanismos y procedimientos que en la práctica tiendan a convertirlos en teorías abstractas e inaplicables.

\subsection{Sentencia T-290 de 1994:}

La norma que establece la primacía de la realidad tiene el sentido de evitar que los derechos fundamentales y las garantías sociales sean meros enunciados abstractos.

\section{Principio de primacía del derecho sustancial.}

El artículo $5^{\circ}$ del Código de Procedimiento Civil colombiano dice que al interpretar la ley procesal, el juez debe tener en cuenta que el objeto de los procedimientos es la efectividad de los derechos reconocidos por la ley sustancial. Esta misma pauta fue recogida en el artículo $228^{\circ}$ de la C.c., mientras que la jurisprudencia ha ofrecido las siguientes pautas:

\subsection{Sentencias T-283/94 y C-383 de 1997:}

La primacía del derecho sustancial significa que los procedimientos legales adquieren su sentido pleno en la protección de los derechos de las personas.

$\checkmark$ Cuando la aplicación de una norma procedimental pierde el sentido instrumental y finalista para el cual fue concebida y se convierte en una mera forma inocua $\mathrm{o}$, más grave aún, contraproducente, el juez debe obviar el trámite formal en beneficio del derecho fundamental afectado. 
Por lo general, la mejor manera de proteger los derechos se encuentra en la observancia de las formalidades y procedimientos consagrados en la ley.

$\checkmark$ Comoquiera que todo procedimiento es un medio para la protección de derechos, el juez debe demostrar en la parte motiva de su fallo que, en el caso específico que analiza, las formalidades impuestas por la ley perdieron tal virtualidad.

La relación entre las formas jurídicas y los derechos sustanciales debe ser analizada en la situación concreta y de acuerdo con el sentido que allí despliegue cada uno de estos elementos.

$\square$ La preferencia del Estado social de derecho por la efectividad de los derechos no significa subestimación per se de las formalidades y de la seguridad jurídica, sino más bien adecuación de medio a fin entre éstas y aquéllos.

\subsection{Sentencias C-026 de 1993 y C-029 de 1993:}

La intención del Constituyente no fue la de eliminar los preceptos legales que establecen formalidades o requerimientos en el trámite de los procesos judiciales.

El propósito de este principio es el de abolir el excesivo rigorismo formal, es decir, la exigencia de múltiples condicionamientos de forma tal que en nada tocan con el fondo del asunto sometido a juicio, o con el derecho en sí mismo considerado, y que su omisión no impide que el fallador profiera decisión definiendo a quién corresponde el derecho.

Hasta aquí los principios para la interpretación constitucional que responden al modelo que hemos tomado como guía. Por supuesto que en la jurisprudencia colombiana se encuentran muchos otros principios que tienen relevancia en el campo del derecho constitucional pero hay que decir que funcionan de otra manera y tienen una estructura diferente. Ejemplos de ellos podrían ser los siguientes, retomando algunos otros significados corrientes de la expresión principio jurídico expuestos con maestría por el profesor Genaro R. Carrió en su famosa conferencia de dictada en Buenos Aires en el año de $1969^{8}$ :

8 Genaro Carrió. Op cit. p. 32 y ss. 
a) Se alude a principio como parte o ingrediente importante de algo, propiedad fundamental, núcleo básico, característica central. En este sentido el derecho constitucional de occidente ofrece ejemplos precisos, acogidos por el derecho colombiano, como el principio de la separación de poderes (Art. $113^{\circ}$ de la Constitución colombiana). Muchos creen que sin separación de poderes no existe Constitución, según la difundida Declaración de los Derechos del Hombre y del Ciudadano de 1789 , Art. $17^{\circ}$.

b) Principio puede utilizarse en el sentido de regla, guía, orientación o indicación general, como en el caso de las llamadas normas programáticas, las cuales podrían ejemplificarse en la C.c. así: el Estado apoyará de manera especial a la mujer cabeza de familia (Art. $43^{\circ}$ de la C.c.); la ley señalará los términos en los cuales la atención básica para todos los habitantes será gratuita y obligatoria (Art. $49^{\circ}$ de la C.c.); el estado promoverá las condiciones para que la igualdad sea real y efectiva y adoptará medidas en favor de grupos discriminados o marginados (Art. $13^{\circ}$ de la C.c.), etc.

c) Se vincula principio con las ideas de fuente generadora, causa u origen, como en el caso del artículo $3^{\circ}$ de la C.c. según el cual «La soberanía reside exclusivamente en el pueblo, del cual emana el poder público» o bien el artículo $94^{\circ}$ de la C.c. a cuyo tenor literal «La enunciación de los derechos y garantías contenidos en la Constitución y en los convenios internacionales vigentes, no debe entenderse como negación de otros que, siendo inherentes a la persona humana, no figuren expresamente en ellos».

d) También se alude a principio para aludir a axiomas, premisas, verdades evidentes, esencia, punto de vista inalterable, como cuando el artículo $5^{\circ}$ de la C.c. postula «la primacía de los derechos inalienables de las personas».

e) Principio en sentido de finalidad, objetivo, propósito o meta. Es así que la C.c. postula que son principios los fines esenciales del Estado y dice cuáles son aquellos fines esenciales (Art. $2^{\circ}$ ), o bien el preámbulo de la C.c.

f) Asimismo, con las ideas de máxima, aforismo o proverbio, un buen ejemplo de los cuales podría ser el artículo $83^{\circ}$ de la C.c. que recoge el principio de la buena fe o el artículo $29^{\circ}$ que prohibe las leyes ex post facto. 
La C.c. contiene una amplia gama de principios que responden a los anteriores focos de significación, pero estos ameritarían un tratamiento aparte. La importancia de un trabajo en ese sentido estriba en el hecho de que sin claridad sobre ellos, como dice Stern, la Constitución corre el peligro de no poder cumplir su función de estabilidad y orden, o bien el peligro de la supremacía de uno de los poderes constituidos dado que no existiría un orden material y estructural fundamental. P Por la misma razón resultaría útil saber cuáles son, cuál es la función y en qué consisten los principios constitucionales: en ellos están contenidas las bases de la institucionalidad, los fundamentos políticoeconómico-sociales, las garantías fundamentales de los ciudadanos, las disposiciones acerca de cómo debe operar el sistema jurídico y las disposiciones rectoras de las relaciones internacionales. Todo el sistema político y jurídico colombiano, puede decirse con certeza, está ligado a la existencia de unos principios. 